\title{
Modification of Classical Mckenzie Treatment for Grade I Lumbar Spondylolythesis with Posterior Lumbar Disc Protrusion
}

\section{Hady Atef Labib Mohammed}

Demonstrator of Physical Therapy for Cardiopulmonary Conditions, Faculty of Physical Therapy, Cairo University, Egypt

*Corresponding author: Hady Atef Labib Mohammed, Demonstrator of Physical Therapy for Cardiopulmonary Conditions, Faculty of Physical Therapy, Cairo University, Egypt, Tel: 00201119699110; E-mail: hady612@hotmail.com

Rec date: Apr 14, 2014, Acc date: Jul 04, 2014, Pub date: Jul 07, 2014

Copyright: $\odot 2014$ Mohammed HAL, et al. This is an open-access article distributed under the terms of the Creative Commons Attribution License, which permits unrestricted use, distribution, and reproduction in any medium, provided the original author and source are credited.

\begin{abstract}
A suggested modification to the classical (Mechanical Diagnosis \& Therapy (MDT) protocols of McKenzie) by substituting the flexion protocol with extension exercises treatment to be applied on grade (I) lumbar spondylolisthesis cases associated with posterior lumbar disc protrusion at level L4/5. This conclusion is supported by a proof case who was treated by extension exercises in 36 sessions of physiotherapy (in addition to the classical rehabilitation), and it was found that all her mechanical symptoms were improved, pain was decreased significantly, dynamic stability of the spine was increased, and signs of upper motor neuron lesion (UMNL) disappeared.
\end{abstract}

Keywords: Mechanical diagnosis and therapy (MDT); Magnetic resonance imaging (MRI); Upper motor neuron lesion (UMNL); Positive babiniski sign (+ve babiniski sign)

\section{Introduction}

According to the classical MDT McKenzie protocol, grade (I) spondylolisthesis is mostly considered as anterior derangement, and therefore corrected with flexion exercises of the spine. This paper is designed to investigate the efficacy of a modification done to this treatment, applying extension exercises of the spine -instead of flexion protocol- to a 65 years old female case who had also posterior lumbar disc protrusion at level L4/5. The extension treatment was recommended to relieve the stress fallen on the spinal cord, in spite of the fact that extension exercises of the spine would be stressful and painful for that case and not right in terms of MDT of McKenzie. However, doing such a modification would be much more important and beneficial for that case than following the classical flexion protocols of the spine [1].

\section{Case description}

The proof case is for a 65 years old female, known to be hypertensive (HTN) but not diabetic (DM). She was diagnosed by the orthopedist as grade (I) lumbar spondylolisthesis and posterior lumbar disc protrusion at level L4/5, ensured by the dynamic X-ray of the lumbosacral spine and magnetic resonance imaging (MRI) of the lumbar spine [2].

Her physician referred her to the physical therapy centre and recommended she should wear the lumbosacral support in addition to doing the physical therapy sessions.

The patient was enrolled in rehabilitation for 2 weeks in the form of classical flexion protocols of McKenzie for the lumbar spine, and a serious deterioration in her symptoms including the pain, and the spinal flexibility was observed. We then stopped the rehabilitation and reassessed the case for modification of her rehabilitation protocols.

\section{Objective}

To rehabilitate that case by the most efficient way of rehabilitation

\section{Methods}

The patient agreed to wear the lumbosacral support as recommended by her physician and to maintain her same dosage of medications during the course in order to not affect the credibility of the study [3].

Basic physical tests were performed as an initial evaluation, and revealed a severe muscle spasm at the lumbosacral spine, detected by palpation of the lumbosacral musculature.

The case was diagnosed as anterior derangement, so according to MDT, the flexion protocols of the lumbar spine of McKenzie should have been followed.

Also a neurological examination was performed to show signs of upper motor neuron lesions (UMNL), as +ve babiniski sign [4].

The patient was subjected to pain assessment using visual analog scale (VAS), and its score was as the following at the beginning of the study: LBP (low back pain) $=8$, While Leg pain and paresthesias $=7$.

In addition, a number of investigations were carried out to help a more accurate case diagnosis

- $\quad$ Dynamic X-ray on the lumbosacral spine showed anterior instability of the spine in the extension position. That's how the spondylolisthesis was diagnosed [5].

- Magnetic Resonance Imaging (MRI) of lumbar spine showed posterior lumbar disc protrusion at level L4/5 [6].

Extension exercises were applied on the lumbar spine in the form of prone positioning, prone on elbow and prone on hand, as a kind of treatment intervention within 36 sessions (3 sessions/week), in addition to the classical soft tissue techniques for the lumbosacral spine, and the core muscle stabilization exercises on the same place (strengthening of transverses abdominis training) $[7,8]$. 
Citation: Mohammed HAL (2014) Modification of Classical Mckenzie Treatment for Grade I Lumbar Spondylolythesis with Posterior Lumbar Disc

Page 2 of 2

\section{Results}

Muscle spasm was decreased, pain level became (=2) according to Visual Analog Scale (VAS), for low back pain \& leg pain became $(=1)$, signs of UMNL had disappeared (babiniski sign became -ve), and dynamic X-ray (repeated at the end of the study) showed less anterior instability when compared with the one done before the treatment intervention.

\section{Discussion}

- McKenzie protocols of the spine therapy perform an initial assessment to the injured cases to know the mechanical underlying cause of their problem, classifying the mechanical insults as follows:

1. Derangement injuries: whether anterior or posterior derangement (anterior derangement is treated with flexion protocols, while posterior derangement is treated with extension protocols).

2. Dysfunction injuries: whether flexion or extension dysfunction (flexion dysfunction is treated with flexion protocols and extension dysfunction is treated with extension protocols).

3. Postural syndrome [9].

- $\quad$ According to MDT, once the case was diagnosed as anterior derangement, she should follow flexion protocols of McKenzie for the anterior derangement of the lumbar spine.

- That patient had posterior lumbar disc protrusion at level L4/5 ensured by the MRI of the lumbar spine, with +ve babiniski sign which ensured UMNL and spinal cord compression at the lumbar spine. This recommended following the extension exercises to relieve that stress fallen on the spinal cord in order to stop signs of UMNL including +ve babiniski sign [10].

- Wearing the lumbosacral support, and keeping medications at same doses, beside doing soft tissue release techniques for the patient, and following the core muscle stabilization exercises for the lumbar spine, in addition to extension exercises for the lumbar spine, all helped to relieve the stress from the spinal cord [11].
- At the end of the study, signs of UMNL-including babiniski signdisappeared (-ve babiniski), while according to the visual analog scale (VAS) pain was significantly decreased, as well as muscle spasm reduction.

\section{Conclusion}

Mechanical diagnosis and therapy (MDT) principles can be modified according to the treatment priorities and ultimate needs of the case, and it is not a steady rule to follow the classical way of therapy in all cases.

\section{References}

1. Koes BW, Van Tulder MW, Ostelo R, Kim Burton A, Waddell G (2001) Clinical guidelines for the management of low back pain in primary care: an international comparison. spine 26: 2504-2514.

2. Burke GL (2013) Backache: From Occiput to Coccyx. MacDonald Publishing.

3. Mckenzie RA (1981) The lumbar spine; Mechanical diagnosis and therapy. Waikanae, spinal publications.

4. Larner AJA (2006) Dictionary of neurological signs. Springer: 50.

5. Walker BF, Muller R, Grant WD (2003) Low back pain in Australian adults : the economic burden. Asia Pac J public health 15: 79-87.

6. Chen R, Cros D, Curra A, Di Lazzaro V, Lefaucheur JP et al.(2009) The clinical diagnostic utility of transcranial magnetic stimulation: report of an IFCN Committee: 504-532.

7. Glossary of osteopathic terminology (2009) American association of colleges of osteopathic medicine: 28.

8. Karageanes, Steven J (2004) Principles of manual sports medicine: 510-511.

9. Petersen T, Thorsen H, Manniche C (1994) Classification of non-specific low back pain: a review of the literature on classifications systems relevant to physiotherapy 4: $265-281$.

10. Lisa $\mathrm{M}$ (2008) Overcoming back and neck pain: 31-37.

11. Hodges PW, Richardson CA (1997) Contraction of the abdominal muscles associated with movement of the lower limb; Physical therapy. 